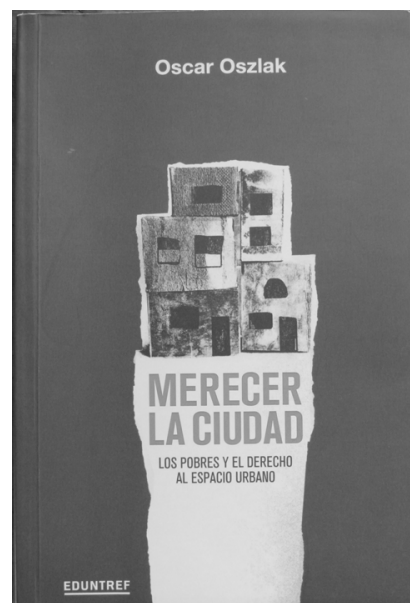

Veinte y seis años después de su primera edición (1991), reaparece Merecer la ciudad, un libro que debería formar parte del currículo y de la biblioteca básica de las licenciaturas y posgrados en estudios urbanos en América Latina. Era una obra prácticamente inconseguible, que en partes circulaba de manera clandestina en PDF y en fotocopias. En ella, como reconoce el propio autor en esta nueva edición, el tiempo transcurrido desde su publicación no ha hecho mella. El origen de la investigación académica que le sirve de sustento, concluida en 1981, fue el deseo de consignar y dejar un testimonio doloroso, pero muy lúcido y rigurosamente académico, del impacto de las políticas públicas impulsadas por la última dictadura militar en Argentina (1976-1983), particularmente sobre la

\section{LA CIUDAD NO ES PARA CUALQUIERA}

MERECER LA CIUDAD.

LOS POBRES Y EL DERECHO AL ESPACIO URBANO

\section{Oscar Ozlak}

Buenos Aires: Eduntraf, Editorial de la Universidad Nacional de Tres de Febrero, 20 i 7 (39I PP.). ISBN: 978-987-4I 5 I-04-9

redistribución espacial de los sectores populares en Buenos Aires. Momentos aciagos en que los derechos ciudadanos fueron confiscados y las instituciones democráticas se vieron arrasadas.

En el prólogo a esta segunda edición, Ozlak explica por qué rehusó reeditar su obra las varias veces en que se lo propusieron: no solo quería actualizarla (con fuentes que en su momento no estaban disponibles o eran inaccesibles), sino que deseaba investigar la evolución de los casos estudiados con el retorno de la democracia, indagar si se resolvieron, reaparecieron o agravaron los problemas investigados. El resultado de esta actualización son dos libros, este que reseñamos, en el cual se actualizan datos que le ayudan al autor a mesurar o reforzar 
sus observaciones; y otro de próxima aparición, con los desenlaces y dilemas de los casos tratados desde el retorno de la democracia en 1983.

Merecer la ciudad analiza cuatro temas: el descongelamiento de alquileres y un nuevo código de edificación que generó un incremento de los precios del suelo y restringió el mercado de vivienda a los sectores de altos ingresos; la erradicación de los asentamientos informales precarios (villas de emergencia) y la expulsión forzada de los villeros; la construcción de autopistas de peaje con expropiación de inmuebles; y la relocalización de las industrias.

Quienes citan con interés y gusto a David Harvey, Neil Smith o Neil Brenner (republicados por las editoriales locales y transnacionales y por diversos medios electrónicos) se sorprenderán al encontrar que en este libro, escrito en 1981 y publicado por primera vez en 1991, Ozlak ya hablaba de una política urbana "revanchista", del "blanqueamiento" de la ciudad, del desplazamiento (in)indirecto y con uso de la fuerza de miles de pobres (nacionales y extranjeros) considerados indignos de residir en Buenos Aires, para destinar esos espacios reconquistados a consumidores "dignos" de la ciudad; es decir, población de mayores ingresos (lo que ahora se llama gentrificación). Además, en este bellísimo libro, Ozlak describe de manera muy simple y clara eso que ahora llamamos "el derecho a la ciudad".

\section{El derecho al espacio urbano}

Para Ozlak, el derecho al espacio urbano consiste en la capacidad de la gente para fijar un lugar donde residir o donde realizar una actividad económica dentro del espacio urbano (derecho de uso), así como participar en la decisión sobre el presente y el futuro de ese espacio, y su derecho a hacerlo. Tal derecho nada tiene que ver con ser propietario o no de ese lugar; también incluye a grupos de población que ocupan el espacio de manera informal, pero se encuentran tolerados o amparados por el Estado.

El espacio urbano es diverso en su accesibilidad y en la calidad de los diferentes servicios urbanos y equipamientos colectivos que alberga, así como en sus condiciones de transporte, fuentes de empleo, opciones de educación y salud. Tales características influyen en la ubicación de la vivienda y las actividades económicas. Para Ozlak, el derecho al espacio urbano es el derecho al uso y goce de las diversas oportunidades económicas y sociales, y bienes desigualmente ubicados, que están asociados al lugar de residencia o a aquel donde se efectúan las actividades económicas. Perder tal derecho implica el desarraigo físico, la desaparición de oportunidades y el deterioro en las condiciones de la vida material de la gente.

\section{Una ciudad para quien la merece}

Tal vez la política urbana más brutal de la dictadura militar (1976-1983), de las analizadas por Ozlak, es el desmantelamiento de los asentamientos precarios de los pobres y la erradicación de miles de personas de bajos ingresos. Los casi ocho ańos de gobierno militar implicaron una profunda reconstitución de la estructura social y urbana de Buenos Aires capital federal, y la "restauración" de un orden imaginado por los militares y las elites socioeconómicas en el 
poder. Ozlak cita textualmente (p. 109) el discurso de la autoridad militar local, según el cual "Vivir en Buenos Aires no es para cualquiera, sino para el que lo merezca”. La justificación era doble: por un lado, el objetivo de preservar la salud y la belleza de la ciudad; y por otro, los estigmas sobre la población que vivía en las villas y que "no requería" la asistencia del Estado: delincuentes, mafiosos y extranjeros que poseían autos, comercios, terrenos y casas; gente que no pagaba impuestos por servicios urbanos y que vivía sin moral alguna.

Para Ozlak, la villa miseria o de emergencia constituye, en la mayoría de los casos, una "estación de paso" en la carrera por la vivienda para los migrantes del campo, que buscan en la ciudad una oportunidad de ascenso social y económico. Sin embargo, para algunos otros también es la "última estación", donde han caído los que perdieron toda esperanza de integrarse al medio urbano. En Buenos Aires esta forma de asentamiento prosperó a partir de 1940 y en el transcurso del tiempo tuvo diferentes respuestas por parte de los gobiernos locales: tolerancia, asistencialismo, diálogo, mejoramiento, reubicación en otras alternativas habitacionales, erradicación puntual. El golpe militar de 1966 lanzó (sin éxito) un plan de erradicación de las villas de emergencia de la Capital (20.000 familias) y de la zona metropolitana o Gran Buenos Aires (70.000 familias), por considerarlas una "aberración urbana".

Con este antecedente, la última dictadura militar (1976-1983) emprendió la erradicación de las villas miseria, llegando a deportar en trenes especiales a sus países de origen a contingentes de bolivianos y paraguayos que allí residían (en el mejor estilo neonazi). Curiosamente, la erradicación fue implementada por la Comisión Municipal de Vivienda (un organismo que debería fomentar y no destruir las soluciones habitacionales). Los desalojos se realizaron en tres fases. Todos los pasos y procedimientos tenían las características de un operativo militar. En la primera etapa se realizaba un diagnóstico físico y social, y se entregaba a los residentes un Certificado de Asentamiento Precario. En la segunda fase se demolían de inmediato casas abandonadas y se impedía la construcción de nuevas; se exigía el pago por la reparación de instalaciones eléctricas; se introdujo en cada villa un Departamento de vigilancia interna que "motivaba" a la población a encontrar una solución habitacional (compra de terreno, vuelta a su país de origen). Para quienes, después de esas fases de amedrentamiento, no se habían ido, venía la fase de erradicación propiamente tal, que incluía "apoyo" para traslado a un terreno propio, retorno a su país y, en pocos casos, apoyos crediticios. En un comienzo la erradicación se concentró en la zona norte, cerca del estadio donde se celebró la Copa del Mundo de 1978, donde residen las clases medias y altas. Según Ozlak, en 1976 se estimaba que había 224.335 personas habitantes en villas de emergencia, pero para 1980 quedaban 40.533. Así, en cuatro años, poco más de 180.000 personas habían sido erradicadas.

\section{Transformaciones en el mercado de vivienda urbana}

En 1976, la Junta Militar sancionó, con una celeridad inusual, la ley 21342, que estableció el gradual descongelamiento de los alquileres de vivienda. Una medida 
pública originada en 1943 -como en otras ciudades latinoamericanas-, que en la segunda posguerra mundial procuraba redistribuir los ingresos a favor del sector de inquilinos. Con el descongelamiento de alquileres, cerca de medio millón de personas (458.103) perdió definitivamente el privilegio que tuvo durante 36 años; de ellas, 186.571 (el $40,7 \%)$ se encontraban en la capital. En ese momento, la brecha entre los alquileres libres y los congelados se había ensanchado enormemente.

Para Ozlak, la hora de la "revancha" había llegado para una burguesía y un gobierno militar que argumentaban que apenas el $1,42 \%$ de la población en régimen de alquiler congelado era jubilada. Así, sostenían, el problema podría resolverse por la gente misma, pues tuvo décadas para ahorrar y conseguir una mejor vivienda. Según Ozlak, entre 1977 y 1978 se iniciaron 46.339 juicios de desalojo en escala metropolitana. Sin embargo, se lamenta el autor, a pesar de la dimensión de la tragedia no hubo un cataclismo social, ni se registraron disturbios o manifestaciones. En el contexto de la Copa del Mundo de 1978, la ciudad asistió insensible a un drama que no trascendió más allá del ámbito de las familias afectadas.

\section{Una misión redentora}

En todos los casos que analiza el autor, se trata de políticas públicas que plantean restricciones reales y potenciales a la radicación urbana de diferentes segmentos de clases populares, que siempre han constituido una amenaza latente para las elites y los grupos en el poder. Todas ellas produjeron, en mayor y menor medida, el desplazamiento de la población de menos ingresos desde el centro hacia la periferia de la metrópoli, donde debió encontrar una solución habitacional y de servicios en las crecientes zonas marginales. Las políticas de los militares tenían un tono "reparador" frente a situaciones que consideraban injustas, antiestéticas y abusivas. Así, se eliminaron los privilegios de las leyes de inquilinato y se restauraron las leyes del mercado de alquiler; se expulsó de la ciudad a los pobres; se construyeron las carreteras que "exigía" una ciudad moderna; y en general se pretendió generar condiciones de calidad de vida acorde a la "jerarquía" de Buenos Aires. Este nuevo orden urbano se basó en tres principios:

- Restauración del libre mercado para maximizar el interés individual y, a través de él, el interés colectivo; (supuestamente) proveer -según la ley de la oferta y la demanda- las viviendas necesitadas por los desprotegidos a menores precios; $y$ fomentar el esfuerzo propio de cada persona para acceder a una vivienda.

- Establecimiento del carácter subsidiario del papel del Estado. Este, que era visto como un mal administrador e incapaz de resolver el déficit de vivienda, debía otorgar incentivos para el libre mercado que indujeran a maximizar el interés individual.

- Desactivación de la acción colectiva, según el principio de que el individuo es el único legítimo defensor de sus intereses.

Los golpistas justificaban sus políticas: en el pasado se hablaba de erradicar las villas de emergencia y las leyes de alquileres se prorrogaban sin que nadie tuviera el valor de tomar una decisión definitiva. Así, la acción estatal, bajo la dictadura militar, se convirtió en una 
empresa redentora que merecía una gratitud eterna: el gobierno militar hizo lo que otros gobiernos querían, pero no se atrevieron a hacer.

\section{Colofón}

Este bellísimo y brutal libro tiene una profunda actualidad, pese a los 37 años de su primera versión mecanografiada y 27 años de su primera publicación. Diversas políticas urbanas en muchas ciudades latinoamericanas, indistintamente de la orientación política de los gobiernos en turno, continúan desplazando a los sectores populares a las periferias distantes, $\mathrm{y}$ embelleciendo $\mathrm{y}$ mejorando selectas áreas urbanas centrales a través de políticas de espacio público, ciclovías, "recuperación” del patrimonio, etcétera. Los códigos y las normas urbanas, como en la Buenos Aires retratada por Ozlak, favorecen la promoción de un mercado inmobiliario de vivienda, comercios y servicios cada vez más caros, dirigidos a clientes con capacidad adquisitiva. Todo ello termina por dejar en evidencia que el actual proyecto de las elites se basa en el principio de que la ciudad latinoamericana no es para cualquiera.

\section{Victor Delgadillo}

Universidad Autónoma de la Ciudad de México,

Ciudad de México, México

E-MAIL: VICTOR.DELGADILLO@UACM.EDU.MX 